\title{
DNA polymerase $X$ from Deinococcus radiodurans implicated in bacterial tolerance to DNA damage is characterized as a short patch base excision repair polymerase
}

Correspondence

Hari S. Misra

hsmisra@barc.gov.in

Received 18 March 2009

Revised 13 June 2009

Accepted 15 June 2009

\author{
Nivedita P. Khairnar and Hari S. Misra \\ Molecular Biology Division, Bhabha Atomic Research Centre, Mumbai-400 085, India
}

\begin{abstract}
The Deinococcus radiodurans $\mathrm{R} 1$ genome encodes an X-family DNA repair polymerase homologous to eukaryotic DNA polymerase $\beta$. The recombinant deinococcal polymerase $\mathrm{X}$ (PolX) purified from transgenic Escherichia coli showed deoxynucleotidyltransferase activity. Unlike the Klenow fragment of $E$. coli, this enzyme showed short patch DNA synthesis activity on heteropolymeric DNA substrate. The recombinant enzyme showed $5^{\prime}$-deoxyribose phosphate (5'$\mathrm{dRP}$ ) lyase activity and base excision repair function in vitro, with the help of externally supplied glycosylase and AP endonuclease functions. A polX disruption mutant of $D$. radiodurans expressing 5'-dRP lyase and a truncated polymerase domain was comparatively less sensitive to $\gamma$-radiation than a pol $X$ deletion mutant. Both mutants showed higher sensitivity to hydrogen peroxide. Excision repair mutants of $E$. coli expressing this polymerase showed functional complementation of UV sensitivity. These results suggest the involvement of deinococcal polymerase $\mathrm{X}$ in DNA-damage tolerance of $D$. radiodurans, possibly by contributing to DNA double-strand break repair and base excision repair.
\end{abstract}

\section{INTRODUCTION}

Cells exposed to DNA-damaging agents produce different types of structural changes depending upon the nature of the DNA damage. DNA strand breaks produced upon radiation exposure are mainly repaired by a recombination process (Shinohara \& Ogawa, 1995). Alkylating agents cause abnormal base methylation, which sometimes leads to formation of AP (apurinic/apyrimidinic) sites on DNA. Methyl groups added onto nucleotide bases are corrected by either respective methyltransferases (Moore et al., 1994) or DNA glycosylases, or both. Escherichia coli contains class I alkyl glycosylase encoded by tagA, and class II glycosylase encoded by alkA. The AlkA enzyme shows a broad range of substrate specificity and can remove a wide range of alkylated bases while TagA glycosylase is highly specific to 3-methyladenine (3-MeAde) and 3-methylguanine (3MeGua) modifications (Bjelland et al., 1993, 1994; O'Brien \& Ellenberger, 2004). Both these enzymes show differential inhibition by excised methylated bases (Tudek

Abbreviations: AP, apurinic/apyrimidinic; BER, base excision repair; $\mathrm{dRP}$, deoxyribose phosphate; MMC, mitomycin C; NER, nucleotide excision repair; PHP, polymerase and histidinol phosphatase; PolX, polymerase $\mathrm{X}$; Pol $\beta$, polymerase $\beta$; T/P, template/primer; UDG, uracil DNA glycosylase.

Two supplementary tables and four supplementary figures are available with the online version of this paper. et al., 1998). Bulky adducts formed by UV action create a block in the replication fork, which is removed by the combined action of multienzyme nucleotide excision machinery followed by the DNA resynthesis step (de Laat et al., 1999). DNA damage produced by oxidizing agents such as hydroxyl and peroxide radicals (Friedberg et al., 1995) causes only slight distortion of DNA molecules and such defects are corrected by the base excision repair (BER) mechanism. The 5'-deoxyribose phosphatase (5'-dRPase) activity in BER DNA polymerases along with DNA glycosylases and AP endonucleases plays an important role in correcting such DNA lesions (Seeberg et al., 1995; Parikh et al., 1999). Non-removal of methylated bases from DNA also induces an SOS response leading to a higher mutation rate (Grzesiuk et al., 2001).

Deinococcus radiodurans $\mathrm{R} 1$ is characterized by its extraordinary tolerance to radiation, desiccation and other DNA-damaging agents (Battista, 2000; Makarova et al., 2001; Blasius et al. 2008). A DNA double-strand break produced by these abiotic agents is repaired in two phases. Phase I is RecA independent and involves the extended synthesis-dependent strand-annealing (ESDSA) process (Zahradka et al., 2006); phase II follows RecA-dependent slow crossover events of homologous recombination (Daly \& Minton, 1996). It is reported that DNA synthesis in $\gamma$ irradiated cells occurs at a much faster rate than in 
unirradiated controls, indicating the higher activity of DNA polymerase during post-irradiation recovery (Zahradka et al., 2006). Apart from replicative DNA polymerases, the $D$. radiodurans genome was annotated for the X-family DNA-repair polymerase (PolX) encoded by DR0467, which is homologous to eukaryotic DNA polymerase $\beta(\operatorname{Pol} \beta)$ (Aravind \& Koonin, 1999). $\operatorname{Pol} \beta$ plays a crucial role in BER and UV lesion bypass DNA synthesis in mammals (Kubota et al., 1996; Servant et al., 2002; Dianova et al., 2004). D. radiodurans is endowed with a strong oxidative stress-tolerance mechanism, which contributes to the extraordinary radiation tolerance of this bacterium (Markillie et al., 1999). D. radiodurans has the complete nucleotide excision repair (NER) system (Evans \& Moseley, 1983; Agostini et al., 1996; Narumi et al., 1997), similar to E. coli, and a poorly understood mechanism of BER. The absence of a lexA mutation effect on the expression of recA and absence of $u m u D C$ in $D$. radiodurans suggested the absence of the SOS response in this bacterium (Narumi et al., 2001; Bonacossa de Almeida et al., 2002; Sheng et al., 2004). However, the role of LexA2 in radioresistance by over expression of $p p r A$ indicated the possibility of LexA2 functioning through a different mechanism in $D$. radiodurans (Satoh et al., 2006). Since $D$. radiodurans contains $\operatorname{PolX}$, a homologue of $\operatorname{Pol} \beta$, along with other components of a BER system, the role of this enzyme in radiation and oxidative stress-induced DNAdamage repair merited investigation.

Here we report the role of PolX in the bacterial response to DNA damage and characterization of the recombinant enzyme for its short patch DNA synthesis and BER activity in vitro. $D$. radiodurans lacking a complete PolX molecule responded differently to $\gamma$-radiation damage compared to cells expressing the $\mathrm{N}$-terminal domain of polymerase. Although these cells showed a relatively smaller effect on mitomycin $\mathrm{C}$ and UV radiation responses, PolX showed functional complementation of E. coli mutants defective for excision repair functions. These results suggest the functional role of this protein in oxidative stress tolerance in $D$. radiodurans and indirectly indicate a less significant role of the polymerase and histidinol phosphatase (PHP) hydrolase domain in polymerase activity in vivo. In addition, the short-length DNA synthesis, 5 '-deoxyribose phosphate $\left(5^{\prime}-\mathrm{dRP}\right)$ lyase activity and the repair of the damaged base in the presence of exogenously added glycosylase and AP endonuclease in vitro might characterize this enzyme as a short patch BER enzyme, and may imply the possible mechanism by which this enzyme could be beneficial in bacterial tolerance to DNA damage.

\section{METHODS}

Bacterial strains, plasmids and growth conditions. Deinococcus radiodurans strain $\mathrm{R} 1$ was a generous gift from Dr M. Schafer (Schafer et al., 2000) and E. coli mutants were obtained from Professor Elzbieta Grzesiuk (Grzesiuk et al., 2001). See Supplementary Table S1, available with the online version of this paper, for details of all strains used. D. radiodurans $\mathrm{R} 1$ was grown at $32{ }^{\circ} \mathrm{C}$ in TGY broth
(0.5\% Bacto Tryptone, $0.1 \%$ glucose, $0.3 \%$ Bacto Yeast Extract). E. coli and its derivatives were grown at $37^{\circ} \mathrm{C}$ in $\mathrm{LB}$ medium supplemented with kanamycin $\left(25 \mu \mathrm{g} \mathrm{ml} \mathrm{ml}^{-1}\right)$ for pET28+ (Novagen) and its derivatives, and ampicillin $\left(100 \mu \mathrm{g} \mathrm{ml}^{-1}\right)$ for pRadgro (Misra et al., 2006) and its derivatives. All the molecular biology grade chemicals, including restriction enzymes and DNAmodifying enzymes, were purchased from Sigma, Roche Biochemicals, New England Biolabs and Bangalore Genei.

Construction of recombinant plasmid for polX expression in $E$. coli. Genomic DNA was prepared from D. radiodurans $\mathrm{R} 1$ as described earlier (Battista et al., 2001). Standard recombinant DNA techniques including plasmid DNA isolation were as described by Sambrook \& Russell (2001). The coding region of polX (White et al., 1999) was PCR amplified from the total genomic DNA of Deinococcus using gene-specific primers (polXF and polXR) as detailed in Supplementary Table S2. The restriction endonuclease sites were added at the $5^{\prime}$ end of the respective primers. PCR was carried out in $50 \mu \mathrm{l}$ containing $50 \mathrm{ng}$ DNA template, $400 \mathrm{nM}$ of each primer, $100 \mu \mathrm{M}$ deoxynucleotide triphosphate, using a GC-rich amplification system (Roche Molecular Biochemicals) for $5 \mathrm{~min}$ at $94{ }^{\circ} \mathrm{C}, 2 \mathrm{~min}$ at $50{ }^{\circ} \mathrm{C}$ and $2 \mathrm{~min}$ at $72{ }^{\circ} \mathrm{C}$ followed by 25 cycles of $2 \mathrm{~min}$ at $94{ }^{\circ} \mathrm{C}$, $2 \mathrm{~min}$ at $50{ }^{\circ} \mathrm{C}$ and $2 \mathrm{~min}$ at $72{ }^{\circ} \mathrm{C}$. The PCR product was sequenced to confirm gene identity and absence of mutation in the coding region of the gene. The $1.7 \mathrm{~kb}$ PCR product was cloned at EcoRI and HindIII sites in pET28a + and at ApaI and $\mathrm{XbaI}$ sites in pRadgro (Misra et al., 2006). The recombinant plasmids containing the polX gene under IPTG-inducible T7 and constitutively expressing groESL promoters were named as pETpolX and pGropolX, respectively.

Generation of polX mutants of $\boldsymbol{D}$. radiodurans. The pPolX : : cat plasmid was constructed by inserting the cat cassette, expressing in Deinococcus, at the SacII site in pETpolX. In brief, the cat gene was PCR amplified from pRAD1 (Meima et al., 2001) using CatF and CatR primers and ligated at the blunt-ended SacII site in pETpolX to yield pPolX : : cat (Supplementary Fig. S1). Recombinant plasmid was linearized with BspMI and transferred into D. radiodurans. The transformants were grown for several generations in TGY supplemented with chloramphenicol $\left(\mathrm{Cm} ; 5 \mu \mathrm{g} \mathrm{m}{ }^{-1}\right)$, and the complete replacement of a wild-type copy of $1.7 \mathrm{~kb}$ polX with $2.7 \mathrm{~kb}$ gene (polX: cat) was confirmed by PCR amplification. Cells lacking the wild-type allele of polX were named as polXnokl.

The polX deletion mutant was generated using protocols similar to that described earlier (Khairnar et al., 2008). In brief, the sequences $1 \mathrm{~kb}$ upstream and $1 \mathrm{~kb}$ downstream of polX (DR0467) were PCR amplified from the $D$. radiodurans genome using NPK1 and NPK2 for downstream and NPK3 and NPK4 for upstream, respectively. These products were cloned sequentially at ApaI-EcoRI followed by BamHI$X b a \mathrm{I}$ sites, respectively. The resultant plasmid pNOKpolX (Supplementary Fig. S2) was linearized with ScaI and transformed into $D$. radiodurans. These cells were grown for several generations in the presence of kanamycin $\left(8 \mu \mathrm{g} \mathrm{m}{ }^{-1}\right)$ until the complete replacement of polX with nptII was achieved, which was confirmed by PCR amplification. The mutant showing the homozygous replacement of polX with nptII was named as polXnok2.

Cell-survival studies. E. coli cells expressing PolX were grown to late exponential phase and treated with different doses of DNA-damaging agents as described earlier (Khairnar et al. 2007; Kota \& Misra, 2006). For $\gamma$-radiation treatment, the late-exponential-phase E. coli cells were treated with different doses of $\gamma$-radiation on ice at a dose rate of $7 \mathrm{~Gy} \mathrm{~min}^{-1}$ (cobalt-60, Gamma cell 220). For UV irradiation, the cells were plated on respective agar plates at different dilutions, airdried and then exposed to different doses of UV radiation at $254 \mathrm{~nm}$, at a dose rate of $0.295 \mathrm{~J} \mathrm{~s}^{-1} \mathrm{~m}^{-2}$, in the dark. Hydrogen peroxide treatment was applied to E. coli using a modified protocol as 
described earlier (Arrage et al., 1993). In brief, E. coli cells were treated with different concentrations of hydrogen peroxide $(0-5 \mathrm{mM})$ for 30 min with vigorous aeration in the dark. Mitomycin C (MMC) treatment was given as described earlier (Keller et al., 2001). Treated cells were plated in triplicate and c.f.u. were scored after $20 \mathrm{~h}$ incubation at $37{ }^{\circ} \mathrm{C}$. The effect of these agents on the cell survival of $D$. radiodurans and its derivatives was studied as described earlier (Misra et al., 2006).

Purification of recombinant PolX and immunoblotting. Transgenic E. coli BL21(DE3) pLysS cells harbouring pETpolX were induced with $100 \mu \mathrm{M}$ IPTG and the cells expressing recombinant protein were used for protein purification by nickel-affinity chromatography using the manufacturer's protocols (Qiagen). In brief, the clear supernatant was mixed with $500 \mu \mathrm{l} 50 \%$ Ni-NTA agarose slurry, and hexahistidine-tagged recombinant protein was eluted from the matrix with elution buffer $\left(50 \mathrm{mM} \mathrm{NaH} \mathrm{PO}_{4}\right.$, $300 \mathrm{mM} \mathrm{NaCl}, 250 \mathrm{mM}$ imidazole, $\mathrm{pH} \mathrm{8.0).} \mathrm{The} \mathrm{fractions} \mathrm{were}$ analysed on SDS-PAGE and the protein sample was dialysed in buffer containing $1 \mathrm{mM}$ DTT. Western blotting using antibodies against PolX and $\mathrm{His}_{6}$ was carried out as described earlier (Sambrook \& Russell, 2001). Protein concentration was determined using Bradford's dye-binding method.

\begin{abstract}
Nucleotide incorporation and polymerase activity characterization. The cross-linking of template/primer (T/P) with enzyme and deoxynucleotidyltransferase activity assay of DNA polymerase was monitored on a UV cross-linked T/P-enzyme complex as described earlier (Misra et al., 1998). In brief, the 19mer oligonucleotide (NPK5) was mixed with 27 mer complementary template (NPK6) in a reaction mixture containing $20 \mathrm{mM}$ Tris/ $\mathrm{HCl}, \mathrm{pH} 7.5,1 \mathrm{mM} \mathrm{MgCl}$ and $1 \mathrm{mM}$ EDTA. The mixture was heated at $95{ }^{\circ} \mathrm{C}$ for $5 \mathrm{~min}$ and allowed to slowly cool to room temperature. The $50 \mathrm{nM} \mathrm{T} / \mathrm{P}$ was mixed with $500 \mathrm{nM}$ enzyme in a reaction mixture containing $50 \mathrm{mM}$ Tris/ $\mathrm{HCl}, \mathrm{pH} 7.5,1 \mathrm{mM}$ DTT, $2 \mathrm{mM} \mathrm{MgCl}_{2}$ and $5 \%$ (v/v) glycerol in a final volume of $50 \mu \mathrm{l}$ and cross-linked with UV light $(320 \mathrm{~nm})$ at $300 \mathrm{MJ} \mathrm{cm}{ }^{-2}$. The enzyme-T/P complex was assayed for its deoxynucleotidyltransferase activity and the incorporation of $\left[\alpha^{32} \mathrm{P}\right] \mathrm{dCTP}$ at the $3^{\prime}$ end of the primer was monitored by $8 \%$ SDS-PAGE followed by autoradiography.
\end{abstract}

The primer extension activity of DNA polymerase was measured as described earlier (Misra et al. 1998). In brief, the $50 \mathrm{nM}$ enzyme was incubated with T/P prepared by annealing the 33mer template (NPK7) with $17 \mathrm{mer}$ (NPK8) primer labelled at the $5^{\prime}$ end in a reaction mixture containing $50 \mathrm{mM}$ Tris/ $\mathrm{HCl}, \mathrm{pH} 7.5,100 \mu \mathrm{M}$ of each $\mathrm{dNTP}$ and $2 \mathrm{mM}$ DTT. The reaction was initiated with $5 \mathrm{mM} \mathrm{MgCl}_{2}$, and 100 -fold excess molar concentration of unlabelled T/P was added. $\mathrm{MgCl}_{2}$ was substituted with $2 \mathrm{mM} \mathrm{MnCl} 2$ in reactions monitoring the effect of manganese ions on enzyme activity. The reaction mixture was incubated for $30 \mathrm{~min}$ at $37{ }^{\circ} \mathrm{C}$ and products were analysed on a $16 \%$ urea-PAGE gel. The signals were detected by autoradiography.

$\mathbf{5}^{\prime}$-dRP lyase and BER activity assay. Preparation of the deoxyribose phosphate (dRP) lyase substrate and 5'-dRP lyase activity assay of recombinant enzyme were carried out essentially as described by Prasad et al. (2003). In brief, a 34mer oligonucleotide (NPK9) having $\mathrm{dU}$ at the 16 th position was labelled with ${ }^{33} \mathrm{P}$ at the $3^{\prime}$ end with terminal deoxynucleotidyltransferase and annealed with 34mer complementary oligonucleotide (NPK10). The dsDNA substrate was treated with uracil DNA glycosylase (UDG) in a standard reaction buffer (New England Biolabs). The $100 \mathrm{nM}$ UDG-treated substrate was incubated with AP endonuclease (APE1, New England Biolabs) and subsequently with $10 \mathrm{nM}$ recombinant PolX at $37{ }^{\circ} \mathrm{C}$ for $30 \mathrm{~min}$ in a reaction mixture containing $50 \mathrm{mM}$ HEPES, $\mathrm{pH} 7.5$, $20 \mathrm{mM} \mathrm{KCl}, 5 \mathrm{mM} \mathrm{MgCl}$, $0.5 \mathrm{mM}$ EDTA and $2 \mathrm{mM}$ DTT. The reaction was terminated with DNA loading dye ( $95 \%$ formamide,
25 mM EDTA, $0.05 \%$ bromophenol blue and $0.05 \%$ xylene cyanol); products were analysed on $8 \mathrm{M}$ urea-10\% PAGE gel and signals were detected by autoradiography.

The BER activity of PolX was assayed using a modification of the protocol described by Kubota et al. (1996). In brief, a 30mer oligonucleotide (NPK11) with internal modification at the 15th position was labelled at the $3^{\prime}$ position with ${ }^{32} \mathrm{P}$ using terminal deoxynucleotidyltransferase and annealed with the complementary oligonucleotide (NPK12) having a normal cytosine complementary to the modified base. The reaction was carried out with 5 units Fpg DNA glycosylase (New England Biolabs) and 1 unit AP endonuclease I (New England Biolabs) in different combinations with $50 \mathrm{nM}$ polymerase and 66 cohesive units of ligase, in vitro. The reaction was carried out in $20 \mu \mathrm{l}$ reaction mixture containing dsDNA oligonucleotide labelled at the $5^{\prime}$ end of the modified oligonucleotide only and $100 \mu \mathrm{M}$ dNTPs as required, under standard assay conditions as described earlier (Kubota et al., 1996).

\section{RESULTS}

\section{The polX disruption mutant expresses truncated polymerase polypeptide}

Two different types of polX mutants, named polXnok1 and polXnok2, were generated in D. radiodurans. In mutant polXnokl, the polX gene was interrupted by the insertion of a cat cassette (Fig. 1). PCR amplification of $D$. radiodurans clones selected on chloramphenicol as selection marker showed a $\sim 850$ bp fragment with cat-specific primers (Fig. 1a) and a $\sim 2.7 \mathrm{~kb}$ DNA fragment that includes polX along with cat, in the polX disruption mutant (Fig. 1b). These cells did not amplify the native polX gene $(1.7 \mathrm{~kb})$ and showed expression of a C-terminal truncated polypeptide of $24 \mathrm{kDa}$ (Fig. 1d). The cat insertion mutant was expected to express the complete $5^{\prime}$-dRP lyase domain and the majority of the polymerase domain before the reading frame is interrupted at amino acid position 184 in the polX gene (Supplementary Fig. S3). However, the $24 \mathrm{kDa}$ chimeric protein comprises a total of 220 amino acids, including $184 \mathrm{~N}$-terminal amino acids of PolX and 36 amino acids of the translation readthrough in the cat cassette sequence before the stop codon (Fig. 1d). Mutant polXnok2 showed the complete replacement of the polX gene with the nptII cassette (Fig. 1c). The homozygous polXnok2 mutant cells showed a complete absence of any protein cross-reacting with PolX antibodies, whereas polXnok1 cells expressed a $24 \mathrm{kDa}$ protein cross-reacting with antibodies and wild-type cells expressed a polypeptide similar to purified proteins and cross-reacting with PolX antibodies (Fig. 1d). This confirmed that both mutants were homozygous for polX mutation and showed different expression of the polymerase domain. These cells were subsequently checked for their DNA-damage responses.

\section{The polX mutants show different responses to oxidative stress and $\gamma$-radiation tolerance}

The two polX mutants were tested for their survival in response to $\gamma$-radiation, MMC and hydrogen peroxide 
(a) Mutant WT Con M

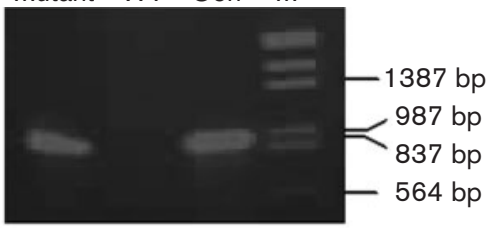

(b)

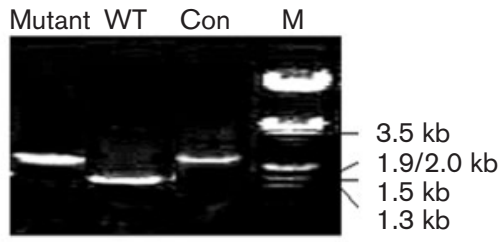

(c)
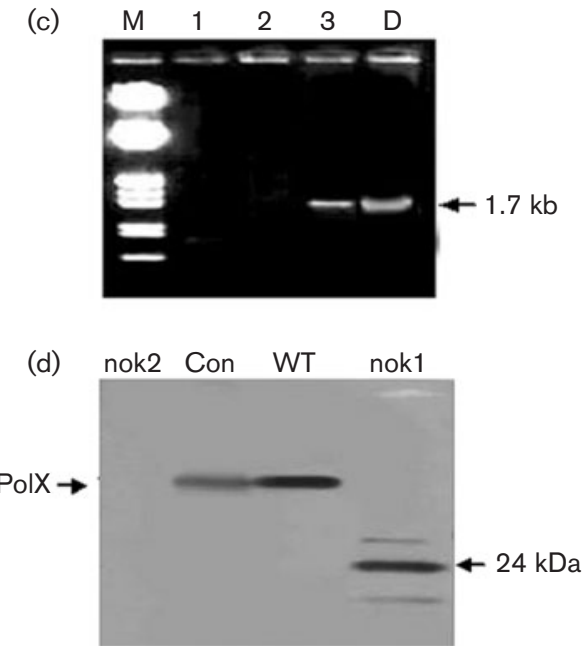

Fig. 1. Generation of PolX mutant derivatives of $D$. radiodurans. $(a, b)$ The complete replacement of the native polX gene with a disrupted copy of polX (polX::cat) in the polXnok1 (nok1) mutant was ascertained by PCR amplification of the cat (a) and polX (b) genes from the genomic DNA from wild-type (WT), mutant cells (Mutant) and pPolX::cat (Con) plasmid. (c) Similarly, PCR amplification of the polX gene was checked in genomic DNA of putative polXnok2 (nok2) clones $(1,2,3)$ and the $D$. radiodurans (D) genome. The sizes of the PCR products, as indicated with arrows, were obtained by comparison with the size markers (M). Clone no. 1 was taken for subsequent studies. (d) Total proteins from wild-type (WT), polXnok1 (nok1), polXnok2 (nok2) mutant and purified PolX (Con) were separated on SDS-PAGE and blotted with antibodies against PolX.

treatment. The polXnok1 cells showed a nearly sixfold decrease in survival relative to wild-type cells after $\gamma$ irradiation at $10 \mathrm{kGy}$ (Fig. 2a), and an almost 1.5 log cycle decrease in tolerance of hydrogen peroxide at $20 \mathrm{mM}$ (Fig. 2b). Interestingly, the polXnok2 mutant was more sensitive to $\gamma$-radiation than the polXnok1 mutant, showing an almost $2 \log$ cycle decrease in $\gamma$-radiation survival at $10 \mathrm{kGy}$. The polXnok2 cells showed a similar response to hydrogen peroxide to that of polXnok1 cells. The slightly higher rate of polXnok2 cell survival than polXnok1 in response to hydrogen peroxide might suggest the possibility of an error-prone repair by truncated polymerase enzyme (PHP minus polymerase domain) in polXnok1 cells. The two mutants differed in their survival after treatment with MMC (Fig. 2d) and UVC (Fig. 2c): unlike polXnok1, the polXnok2 cells showed sensitivity to higher doses of UV radiation and to longer exposure with MMC $\left(20 \mu \mathrm{g} \mathrm{ml}^{-1}\right)$ as compared to wild-type. The differential effect of polX mutation on $\gamma$-radiation response and relatively higher sensitivity to hydrogen peroxide suggest that PolX has a greater role in oxidative stress tolerance of $D$. radiodurans. The higher sensitivity of polXnok2 cells to $\gamma$-radiation than polXnok 1 cells indicated the enigmatic role of the PHP domain in PolX activity regulation.

\section{Deinococcal PolX shows typical short patch DNA repair characteristics}

The polX gene (DR0467) of D. radiodurans was cloned in pET28a + to yield pETpolX and recombinant protein was expressed under the T7 inducible promoter in E. coli BL21 (Supplementary Fig. S4). Recombinant PolX was purified from transgenic E. coli to near homogeneity (Fig. 3a) and was checked for its nucleotide incorporation specificity and primer extension activity. The enzyme-T/P complex was cross-linked by UV irradiation and incubated with dNTP mixture containing $\left[\alpha_{-}{ }^{32} \mathrm{P}\right] \mathrm{dCTP}$ as one of the deoxynucleotides. Since the enzyme was cross-linked with DNA, its intermolecular dynamics would be restricted and the incorporation of $\left[\alpha-{ }^{32} \mathrm{P}\right] \mathrm{dCTP}$, a complementary base to $\mathrm{G}$ in the template, would be possible only if the enzyme has bound DNA in polymerase mode. The results showed that PolX binds $\mathrm{T} / \mathrm{P}$ in polymerase mode and could add $\left[\alpha-{ }^{32} \mathrm{P}\right] \mathrm{dCTP}$ at the primer terminus (Fig. 3b) in the enzyme-T/P cross-linked complex. SDS-PAGE analysis followed by autoradiography showed a major band of about $84 \mathrm{kDa}$ (enzyme-T/P) along with two smaller-sized products of approximately $27 \mathrm{kDa}$ and $40 \mathrm{kDa}$. The nature of the smaller-sized products is not clear. However, the possibility of recombinant PolX undergoing proteolytic cleavage into the polymerase domain cannot be ruled out. Antibodies generated against the complete PolX molecule reacted with an additional smaller-sized protein of $D$. radiodurans (Fig. 1d). E. coli DNA polymerase I undergoes in vivo cleavage into different smaller-sized products exhibiting deoxynucleotidyltransferase activity in gel (Yoshida \& Cavalieri, 1971). Our results confirmed earlier reports that the recombinant PolX of $D$. radiodurans is an active enzyme, which binds the double-stranded DNA substrate in its polymerase mode. The primer extension ability of PolX was tested using $5^{\prime}$-radiolabelled primer in $\mathrm{T} / \mathrm{P}$ and incubation with unlabelled dNTPs. PolX showed addition of only two nucleotides in a single binding event at the primer end while E. colis Klenow fragment showed full-length primer extension (Fig. 3c). It was previously shown that a putative $D$. radiodurans polX gene encoded an active DNA polymerase enzyme with hairpin nuclease activity (Lecointe et al., 2004; Blasius et al., 2006). While 

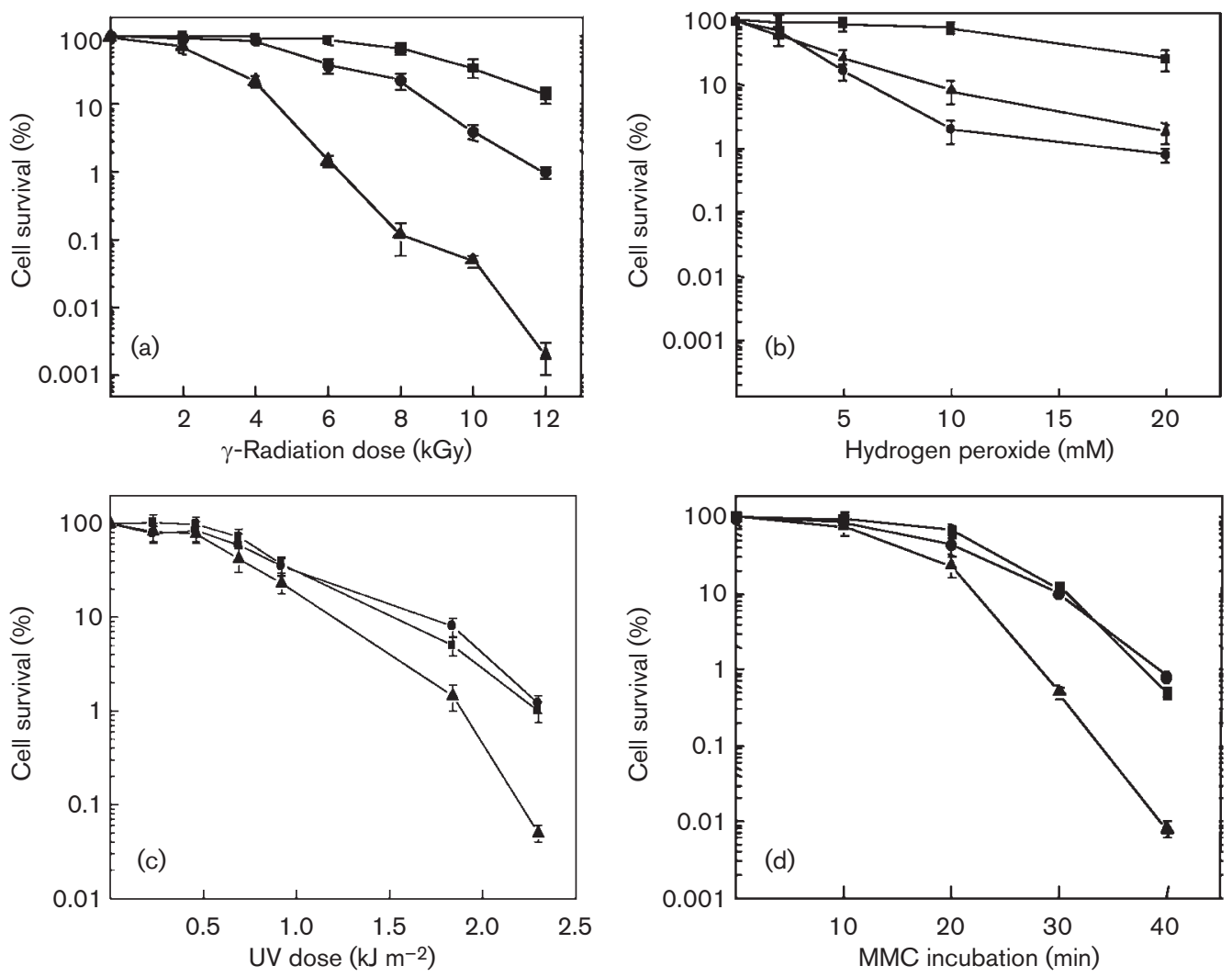

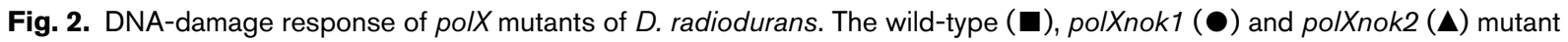
cells were treated with $\gamma$-radiation (a), hydrogen peroxide (b), UV irradiation (254 $\mathrm{nm}$ ) (c) and different periods with MMC $\left(20 \mu \mathrm{g} \mathrm{ml}^{-1}\right)(\mathrm{d})$, and cell survival was monitored as described in Methods.

confirming the polymerase activity of the enzyme, the short patch DNA synthesis nature of this polymerase was also evident from our study.

\section{Deinococcal PolX shows 5'-dRP lyase and BER activity}

The short patch DNA polymerase function of PolX was correlated with its role in BER. The $5^{\prime}$-dRP lyase and BER activity of this polymerase was assayed with internally modified double-stranded oligonucleotides using standard protocols. For $5^{\prime}$-dRP lyase activity, the $3^{\prime}$-labelled dUDNA substrate (dU-S) was treated with UDG and the substrate with the apurinic site was incubated with AP endonuclease with and without recombinant deinococcal PolX. The results showed the release of an oligonucleotide close to $19 \mathrm{nt}$ in length (dRP-S) upon AP endonuclease treatment (Fig. 4). The incubation of PolX along with AP endonuclease resulted in the conversion of the majority of the dRP-S into an $18 \mathrm{mer}$ product. Since dRP-S was generated from AP endonuclease action on UDG-treated substrate, it would have a dRP residue from the apurinic site located at its $5^{\prime}$ end. The generation of an $18 \mathrm{mer}$ product from dRP-S, which could have resulted from the removal of the dRP residue, suggests the presence of $5^{\prime}$ dRP lyase activity in this enzyme.

For BER activity, the 8-oxoG incorporated oligonucleotide annealed with normal complementary oligonucleotide (Fig. 5a) was incubated with recombinant PolX in different combinations and permutations of recombinant DNA glycosylase, AP endonuclease and DNA ligase. The results showed the addition of a single nucleotide by this polymerase at the lesion produced by combined action of glycosylase and AP endonuclease (Fig. 5). Incubation of modified dsDNA substrate with glycosylase, AP endonuclease and PolX, separately (Fig. 5b, lanes 2-4), did not show the cleavage of labelled nucleotide at the modified base position, i.e. 15. However, incubation of DNA substrate with glycosylase, AP endonuclease and PolX together, without DNA ligase, cleaved the dsDNA substrate at the 15th position and cleavage products of $16 \mathrm{nt}$ were seen (Fig. 5b, lanes 5-9). In samples incubated with PolX, the release of a product of $15 \mathrm{nt}$, possibly due to $5^{\prime}$-dRP lyase activity of PolX, was also seen. Incubation of these enzymes with DNA ligase gave a full-length product in the presence of dGTP (Fig. 5b, lane 11). Incubation with dTTP (lane 10) and dCTP (lane 13) did not show recovery of fulllength DNA product. However, low activity was also 
(a)

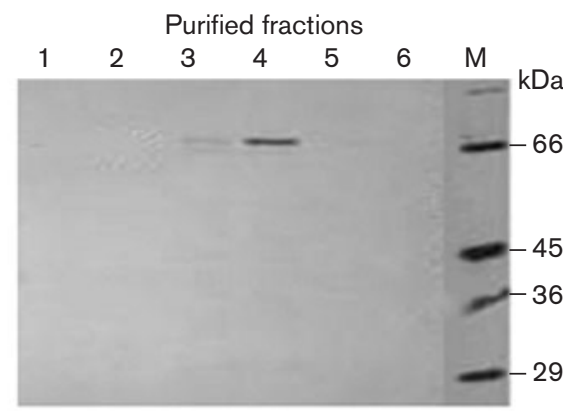

(b)

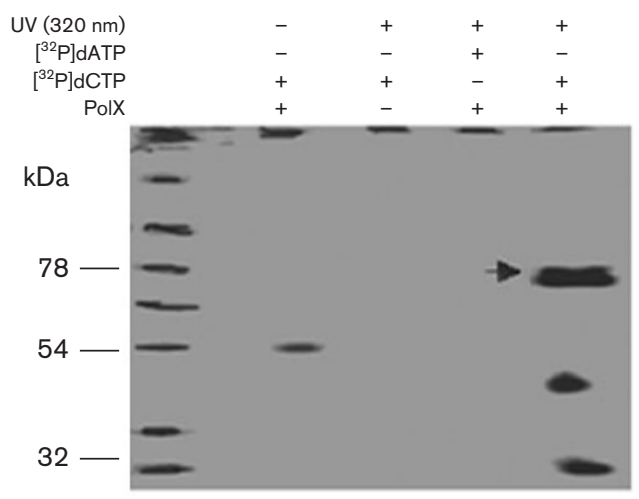

(c)

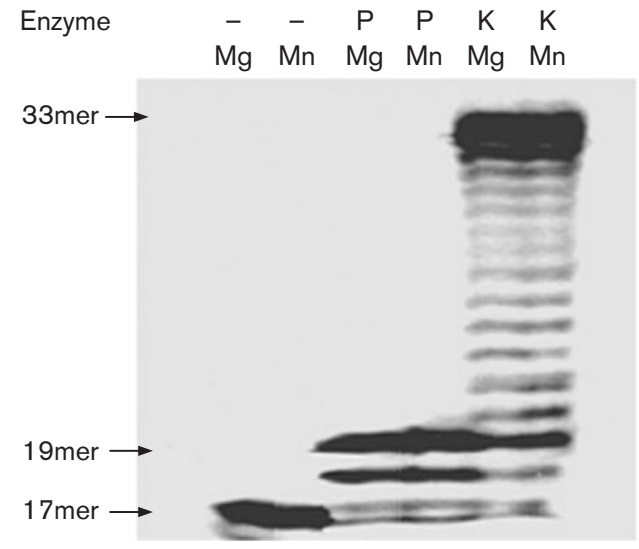

Fig. 3. Activity characterization of recombinant PolX. The purified deinococcal DNA PoIX (a) as shown in fraction no. 4 was taken for further enzyme activity assay. (b) The T/P primer was UV crosslinked with polymerase enzyme and incubated either with dCTP, a correct nucleotide, or with dATP for incorporation at the primer terminus. (C) The primer extension assay was carried out either with PolX $(\mathrm{P})$ or with Klenow fragment of $E$. coli $(\mathrm{K})$ in the presence of $\mathrm{Mg}^{2+} / \mathrm{Mn}^{2+}$ as described in Methods and products were separated by $12 \%$ urea-PAGE gel followed by autoradiography.

observed in the presence of dATP alone (Fig. 5b, lane 12), indicating the possibility of this enzyme lacking stringent substrate specificity in vitro. The regeneration of full-length oligonucleotides from the glycosylase and AP endonuclease cleaved fragments could be possible only when $5^{\prime}-\mathrm{dRP}$ is enzymically replaced with normal dGTP/dATP. This

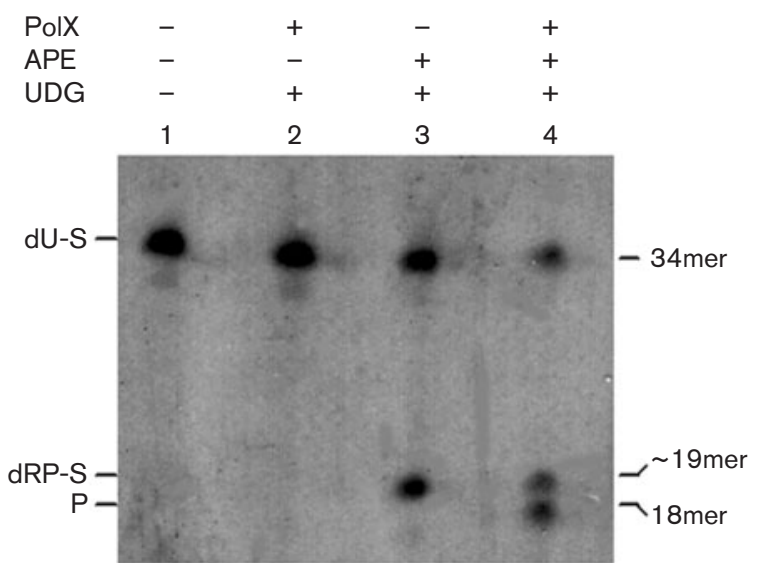

Fig. 4. The 5'-dRP lyase activity of deinococcal PolX. The recombinant PolX was assayed for $5^{\prime}$-dRP lyase activity using $3^{\prime}$-labelled $\left[{ }^{33} \mathrm{P}\right] \mathrm{dU}$-substrate (dU-S, 1) as described in Methods. The UDG-treated dU template (2) was incubated with AP endonuclease (APE) (3) to yield 5'-dRP substrate (dRP-S). The AP-treated dU-S was incubated with PolX (4) and the reaction mixture containing product $(P)$ of the PolX reaction was analysed by $10 \%$ urea-PAGE and radiolabelled products detected by autoradiography.

further supports the presence of $5^{\prime}$-dRP lyase activity for this enzyme (Fig. 4) and suggests the role of recombinant PolX in the repair of modified bases in vivo by combined action with other BER enzymes such as DNA glycosylase and uncharacterized AP endonuclease.

\section{Deinococcal PolX complements AlkA glycosylase and UvrA deficiencies in $E$. coli}

To study the phenotypic effect of PolX in E. coli AB1157 and its mutant derivatives, the polX coding sequence along with six histidine codons was PCR amplified from pETpolX and subcloned in pRadgro, under the $\mathrm{P}_{\text {groESL }}$ promoter, to yield pGropolX (Fig. 6a). E. coli mutants defective in BER and NER (Supplementary Table S1) were transformed with pGropolX. Since pGropolX is expected to express the recombinant protein with an $\mathrm{N}$-terminal hexahistidine tag, the expression of $\mathrm{His}_{6}$-PolX in various mutant backgrounds was ascertained by immunoblotting using hexahistidine antibodies and also with anti-PolX serum. Both anti-His antibodies (Fig. 6b) and anti-PolX serum cross-reacted with a similar protein band from $E$. coli cells harbouring pGropolX, while the cells harbouring the expression vector did not show cross-reactivity of any other proteins with both antibodies. Anti-PolX serum cross-reacted with only one protein band from pGropolXexpressing clones (data not shown). This indicated the expression of recombinant PolX in E. coli under the groESL promoter of $D$. radiodurans. The functioning of the deinococcal groESL promoter in E. coli was demonstrated earlier (Kota \& Misra, 2006). 


\section{(a) \\ 5' GOOGGAATTOCATAX'XCGTTACOCTCGGCGC3'-32P 3' CGGCCTTAAGGTATCGCAATGGGACOCGCG5'}

\section{( $\mathrm{X}=8$-oxoguanidine)}

(b)

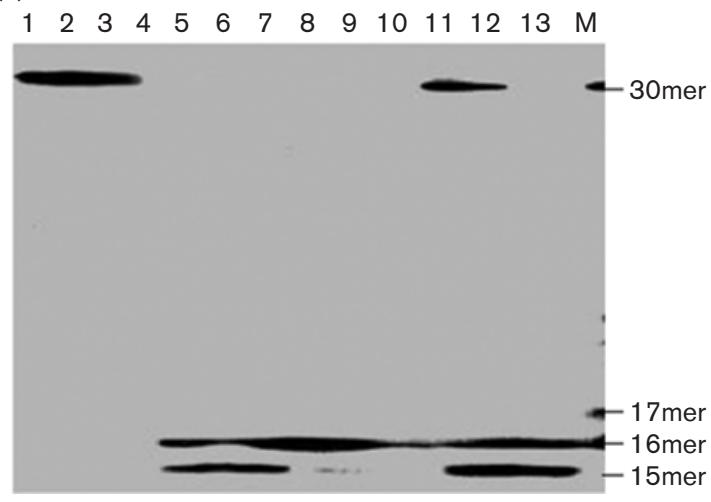

Fig. 5. BER activity of DNA PoIX. (a) The double-stranded oligonucleotide substrate was prepared with the ${ }^{32} \mathrm{P}$-labelled modified oligonucleotide having 8 -oxo-guanidine $\left(^{*}\right)$ at the 15 th position and annealed with complementary olignucleotides. (b) The labelled substrate (1) was mixed with Fpg glycosylase (2), AP endonuclease (3) and polymerase (4) separately, and together without DNA ligase (5-9) and with DNA ligase (10-13) in the presence of dTTP $(5,10), \operatorname{dCTP}(6,13)$, dGTP $(8,11)$, dATP $(7$, 12) and all four dNTPs (9) under standard excision repair assay conditions as described in Methods. The products were analysed by $16 \%$ urea-PAGE followed by autoradiography.

The effect of transgenic PolX on the DNA-damage response of these $E$. coli mutants was checked. The results showed a 2 log cycle improvement in UVC tolerance of the alkA (Fig. 7a) and uvrA (Fig. 7b) mutants, although this did not equal the basal level of wild-type tolerance. The alkA and $u v r A$ mutants did not show significant improvement in their resistance to hydrogen peroxide, MMC and $\gamma$-radiation exposure (data not shown). Surprisingly, the tagA mutant expressing PolX showed contrasting responses to UV and MMC effects (Figs 7 and 8). On the one hand, these cells showed higher sensitivity to UVC radiation, which was suppressed by the additional mutation in the alkA gene (Fig. 7a). On the other hand, they showed nearly fourfold improvement in MMC tolerance as compared to $\operatorname{tag} A$ mutant control at a concentration of $1 \mu \mathrm{g} \mathrm{ml}$ (Fig. 8). AB1157 expressing PolX showed improved tolerance to MMC as compared to the control (Fig. 8). MMC is a bifunctional agent that causes alkylation of bases and cross-linking on DNA, which can be repaired by both excision repair and double-strand break repair mechanisms. The improved MMC tolerance of wild-type cells expressing PolX suggested the role of this polymerase in these DNA repair processes.

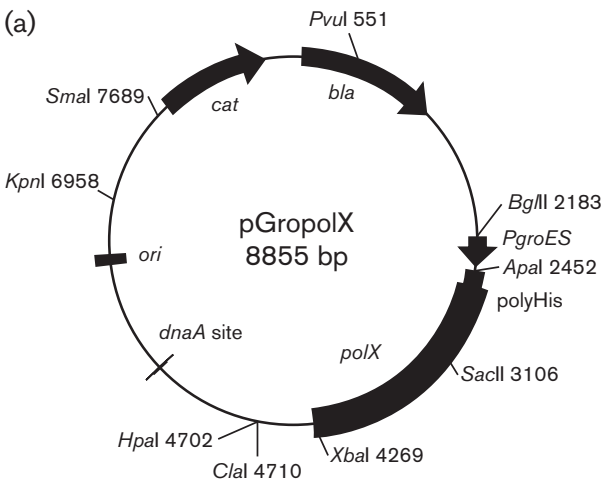

(b)

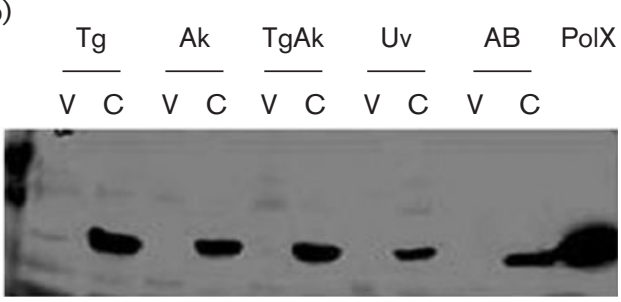

Fig. 6. Cloning of polX in $E$. coli expression vector and confirmation of recombinant protein expression by immunoblotting. polX along with six histidine codons was cloned in pRadgro (a), and transformed into $E$. coli $\operatorname{tag} A(\mathrm{Tg})$, alkA (Ak), tagAalkA (TgAk), uvrA (Uv) mutants and the parental strain AB1157 (AB). The expression of recombinant protein (PolX) in transgenic cells (C) and its absence in vector controls ( $V$ ) was confirmed by immunoblotting with anti-histidine serum (b).

\section{DISCUSSION}

This paper reports (i) the in vivo role of an X-family DNA polymerase in oxidative stress and $\gamma$-radiation tolerance of D. radiodurans and (ii) the short patch DNA synthesis and BER activity of recombinant PolX, in vitro. The different $\gamma$ radiation responses of the polX mutant lacking the complete polymerase molecule and the mutant lacking only the PHP domain suggest a role for the N-terminal polymerase in $\gamma$-radiation tolerance and DNA repair. Hydrogen peroxide affected both categories of polX mutants more than wild-type cells, supporting the role of this polymerase in oxidative stress tolerance. Earlier studies have reported a similar effect of polX deletion mutation on the $\gamma$-radiation response of $D$. radiodurans (Lecointe et al., 2004).

PolX shows amino acid sequence similarities with eukaryotic $\operatorname{Pol} \beta$ (Aravind \& Koonin, 1999), which has been shown to be a BER and DNA lesion bypass repair enzyme (Kubota et al., 1996; Servant et al., 2002; Dianova et al., 2004). Unlike replicative DNA polymerases such as DNA Pol $\alpha$, DNA Pol $\gamma$ and DNA PolIII, which can polymerize long-stretch DNA (Holmes et al., 1990; Lahue et al., 1989), the DNA repair $\operatorname{Pol} \beta$ catalyses the short patch BER function by incorporation of one or two nucleotides on damaged sites similar to very short patch repair in bacteria 

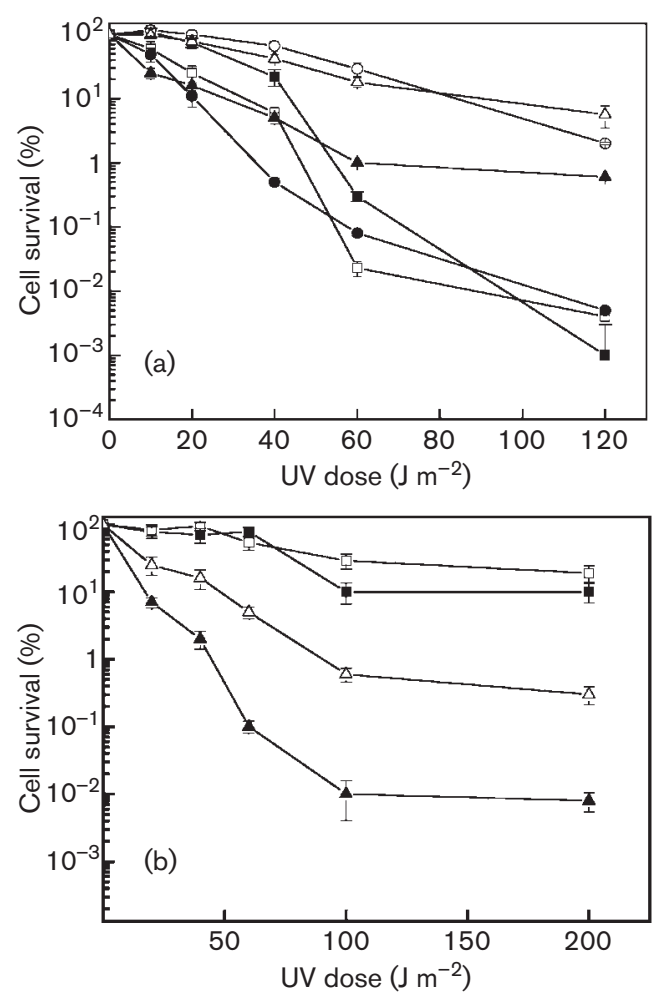

Fig. 7. Effect of PolX expression on the UV response of excision repair mutants. (a) E. coli mutants $\operatorname{tag} A(\boldsymbol{\square}, \square)$, alkA $(\boldsymbol{\bullet}, \bigcirc)$, $\operatorname{tagAalk} A(\boldsymbol{\Lambda}, \triangle)$ and $(\mathrm{b})$ uvrA $(\boldsymbol{\Lambda}, \triangle)$ and parental strain AB1157 $(\boldsymbol{\square}, \square)$ transformed with pGropolX (open symbols) were treated with UV radiation $(254 \mathrm{~nm})$ and the effect on cell survival was compared with untransformed controls (filled symbols) as described in Methods.

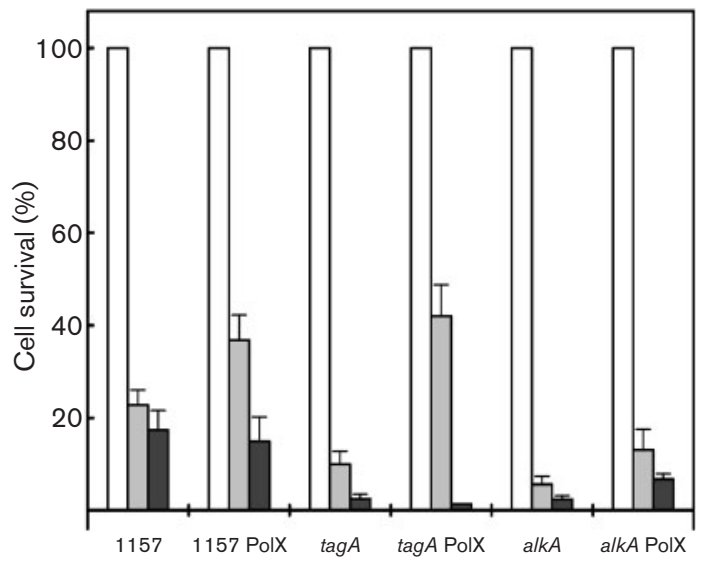

Fig. 8. Effect of $\mathrm{MMC}$ on cell survival of $E$. coli expressing PolX. $E$. coli $\operatorname{tag} A$ and alkA mutants and the parental strain $\mathrm{AB} 1157$ expressing PolX (tagA PolX, alkA PolX and 1157 PolX, respectively) were treated with $\mathrm{MMC}$ at $1 \mu \mathrm{g} \mathrm{ml}^{-1}$ (light grey bars) or $2 \mu \mathrm{g}$ $\mathrm{ml}^{-1}$ (dark grey bars) for $30 \mathrm{~min}$ and cell survival was compared with untreated controls (white bars).
(Wiebauer \& Jiricny, 1990; Lieb, 1987). Our results from primer extension activity assay (Fig. 3c), 5'-dRP lyase assay (Fig. 4) and BER assay (Fig. 5) strongly support the possibility of PolX acting as a short patch DNA repair polymerase similar to eukaryotic $\operatorname{Pol} \beta$, and it may not necessarily be a processive and replicative enzyme. However, the role of a processive DNA polymerase A of $D$. radiodurans $\mathrm{R} 1$ in lesion bypass activity has also been reported recently (Heinz \& Marx, 2007). The recently published 3D structure of PolX solved at $2.46 \AA$ resolution indicated an unusual stretched-out conformation instead of the usual closed right-hand conformation as normally observed with other DNA polymerases (Leulliot et al., 2009). The functional complementation of PolX to the UVC response of $u v r A$ and alkA mutants and wild-type E. coli cells (Fig. 7) suggests the contribution of this polymerase in UV repair of $E$. coli. Since the polX deletion mutant of $D$. radiodurans showed marginal sensitivity to UVC at higher doses and greater improvement in UVC response of $E$. coli, the role of this polymerase in UV tolerance seems to require the otherwise functional SOS response in the host cell. The higher sensitivity of the $\operatorname{tag} A$ mutant expressing PolX was suppressed by alkA mutation in alkAtagA double mutants. Similarly, the alkAtagA double mutant showed higher tolerance to UVC as compared to single mutations (Fig. 7a). It has been suggested that the accumulation of 3-MeAde and 7MeGua on the genome of alkAtagA double mutants of $E$. coli, respectively, induces the SOS response (Grzesiuk et al., 2001). Therefore, the possibility of PolX contributing to excision/SOS repair of UV-modified bases in E. coli could be speculated. Functional complementation of eukaryotic Y-family DNA polymerase in DNA repair of E. coli lacking non-replicative Y-family polymerases such as UmuDC and DinB has been demonstrated (Yamada et al., 2006).

Also, it is noteworthy that polX mutants differing in the expression of the N-terminal domain of PolX showed different responses to $\gamma$-radiation and MMC. This indicates, although indirectly, the lesser importance of the PHP domain in the N-terminal domain activity of this DNA polymerase. Recently, the crystal structure of this polymerase was resolved at $2.46 \AA$, which also clearly suggested that the nuclease active site of the PHP domain is obstructed by the polymerase domain (Leulliot et al., 2009). On the contrary, this enzyme showed the short patch DNA synthesis and BER function in conjunction with other BER proteins in vitro, as observed in this study, and others have also reported the endonuclease activity of this enzyme (Lecointe et al., 2004), in vitro. These findings invite speculation about a novel mechanism of PHP and polymerase domain interactions during catalytic reactions both in vitro and in vivo and would be worth investigating independently. An orthologue of the PolX reported from Bacillus subtilis shows the identical arrangement of PHP and polymerase domains (Baños et al., 2008). The action of the B. subtilis enzyme on DNA gaps with a downstream $5^{\prime}$ phosphate group, a prerequisite reaction for BER, has been 
demonstrated. Thus the $5^{\prime}$-dRP lyase activity observed with the D. radiodurans PolX (Fig. 4) and earlier findings on the $B$. subtilis enzyme suggest that polymerases having an $\mathrm{N}$ terminal polymerase domain similar to $\operatorname{Pol} \beta$ and a PHP domain similar to the $B$. subtilis enzyme would come under the category of BER polymerase. Taken together, the results presented here support the close functional similarities of PolX with $\operatorname{Pol} \beta$ in short patch BER in vitro, and the involvement of this enzyme in bacterial oxidative stress tolerance and UV resistance, possibly by a short patch excision repair mechanism.

\section{ACKNOWLEDGEMENTS}

The authors are grateful to Dr Elzbeita Grzesiuk, Polish Academy of Sciences, Poland, for the kind gift of E. coli mutants and to Dr S. K. Apte, Bhabha Atomic Research Centre, Mumbai, for his comments on data interpretation and preparation of the manuscript.

\section{REFERENCES}

Agostini, H. J., Carroll, J. D. \& Minton, K. W. (1996). Identification and characterization of uvrA, a DNA repair gene of Deinococcus radiodurans. J Bacteriol 178, 6759-6765.

Aravind, L. \& Koonin, E. V. (1999). DNA polymerase $\beta$ like nucleotidyltransferase superfamily: identification of three new families, classification and evolutionary history. Nucleic Acids Res 27, 1609-1618.

Arrage, A. A., Phelps, T. J., Benoit, R. E. \& White, D. C. (1993). Survival of subsurface microorganisms exposed to UV radiation and hydrogen peroxide. Appl Environ Microbiol 59, 3545-3550.

Baños, B., Lázaro, J. M., Villar, L., Salas, M. \& de Vega, M. (2008). Characterization of a Bacillus subtilis $64 \mathrm{kDa}$ DNA polymerase $\mathrm{X}$ potentially involved in DNA repair. J Mol Biol 384, 1019-1028.

Battista, J. R. (2000). Radiation resistance: the fragments that remain. Curr Biol 10, R204-R205.

Battista, J. R., Park, M. J. \& McLemore, A. E. (2001). Inactivation of two homologous proteins presumed to be involved in the desiccation tolerance of plants sensitizes Deinococcus radiodurans $\mathrm{R} 1$ to desiccation. Cryobiology 43, 133-139.

Bjelland, S., Bjøras, M. \& Seeberg, E. (1993). Excision of 3methylguanine from alkylated DNA by 3-methyladenine DNA glycosylase I of Escherichia coli. Nucleic Acids Res 21, 2045-2049.

Bjelland, S., Birkeland, N. K., Benneche, T., Volden, G. \& Seeberg, E. (1994). DNA glycosylase activities for thymine residues oxidized in the methyl group are functions of the AlkA enzyme in Escherichia coli. J Biol Chem 269, 30489-30495.

Blasius, M., Shevelev, I., Jolivet, E., Sommer, S. \& Hübscher, U. (2006). DNA polymerase X from Deinococcus radiodurans possesses a structure-modulated $3^{\prime} \rightarrow 5^{\prime}$ exonuclease activity involved in radioresistance. Mol Microbiol 60, 165-176.

Blasius, M., Sommer, S. \& Hubscher, U. (2008). Deinococcus radiodurans: what belongs to the survival kit? Crit Rev Biochem Mol Biol 43, 221-238.

Bonacossa de Almeida, C., Costa, G., Sommer, S. \& Bailone, A. (2002). Quantification of RecA protein in Deinococcus radiodurans reveals involvement of RecA, but not LexA, in its regulation. Mol Genet Genomics 268, 28-41.
Daly, M. J. \& Minton, K. W. (1996). An alternative pathway of recombination of chromosomal fragments precedes recA-dependent recombination in the radioresistant bacterium Deinococcus radiodurans. J Bacteriol 178, 4461-4471.

de Laat, W. L., Jaspers, N. G. \& Hoeijmakers, J. H. (1999). Molecular mechanism of nucleotide excision repair. Genes Dev 13, 768-785.

Dianova, I. I., Sleeth, K. M., Allinson, S. L., Parsons, J. L., Breslin, C., Caldecott, K. W. \& Dianov, G. L. (2004). XRCC-1-DNA polymerase $\beta$ interaction is required for efficient base excision repair. Nucleic Acids Res 32, 2550-2555.

Evans, D. M. \& Moseley, B. E. (1983). Roles of the $u v s C$, $u v s D$, $u v s E$, and $m t c A$ genes in the two pyrimidine dimer excision repair pathways of Deinococcus radiodurans. J Bacteriol 156, 576-583.

Friedberg, E. C., Bardwell, A. J., Bardwell, L., Feaver, W. J., Kornberg, R. D., Svejstrup, J. Q., Tomkinson, A. E. \& Wang, Z. (1995). Nucleotide excision repair in the yeast Saccharomyces cerevisiae: its relationship to specialized mitotic recombination and RNA polymerase II basal transcription. Philos Trans R Soc Lond B Biol Sci 347, 63-68.

Grzesiuk, E., Gozdek, A. \& Tudek, B. (2001). Contribution of E. coli AlkA, TagA glycosylases and UvrABC-excinuclease in MMS mutagenesis. Mutat Res 480-481, 77-84.

Heinz, K. \& Marx, A. (2007). Lesion bypass activity of DNA polymerase A from the extremely radioresistant organism Deinococcus radiodurans. J Biol Chem 282, 10908-10914.

Holmes, J., Jr, Clark, S. \& Modrich, P. (1990). Strand-specific mismatch correction in nuclear extracts of human and Drosophila melanogaster cell lines. Proc Natl Acad Sci U S A 87, 5837-5841.

Keller, K. L., Overbeck-Carrick, T. L. \& Beck, D. J. (2001). Survival and induction of SOS in Escherichia coli treated with cisplatin, UVirradiation, or mitomycin $\mathrm{C}$ are dependent on the functions of the RecBC and RecFOR pathways of homologous recombination. Mutat Res 486, 21-29.

Khairnar, N. P., Kamble, V. A., Mangoli, S. H., Apte, S. K. \& Misra, H. S. (2007). Involvement of a periplasmic protein kinase in DNA strand break repair and homologous recombination in Escherichia coli. Mol Microbiol 65, 294-304.

Khairnar, N. P., Kamble, V. A. \& Misra, H. S. (2008). RecBC enzyme overproduction affects $\mathrm{UV}$ and gamma radiation survival of Deinococcus radiodurans. DNA Repair (Amst) 7, 40-47.

Kota, S. \& Misra, H. S. (2006). PprA: a protein implicated in radioresistance of Deinococcus radiodurans stimulates catalase activity in Escherichia coli. Appl Microbiol Biotechnol 72, 790-796.

Kubota, Y., Nash, R. A., Klungland, A., Schar, P., Bames, D. E. \& Lindahl, T. (1996). Reconstitution of DNA base excision-repair with purified human proteins: interaction between DNA polymerase $\beta$ and the XRCC-1 protein. EMBO J 15, 6662-6670.

Lahue, R. S., Au, K. \& Modrich, G. P. (1989). DNA mismatch correction in a defined system. Science 245, 160-164.

Lecointe, F., Shevelev, I. V., Bailone, A., Sommer, S. \& Hubscher, U. (2004). Involvement of an $X$ family DNA polymerase in double stranded break repair in the radioresistant bacterium Deinococcus radiodurans. Mol Microbiol 53, 1721-1730.

Leulliot, N., Cladière, L., Lecointe, F., Durand, D., Hübscher, U. \& van Tilbeurgh, H. (2009). The X-family DNA polymerase from Deinococcus radiodurans adopts a non-standard extended conformation. J Biol Chem 284, 11992-11999.

Lieb, M. (1987). Bacterial genes mutL, mutS, and $\mathrm{dcm}$ participate in repair of mismatches at 5-methylcytosine sites. J Bacteriol 169, 52415246. 
Makarova, K. S., Aravind, L., Wolf, Y. I., Tatusov, R. L., Minton, K. W., Koonin, E. V. \& Daly, M. J. (2001). Genome of extremely radiationresistant bacterium Deinococcus radiodurans viewed from the perspectives of comparative genomics. Microbiol Mol Biol Rev 65, 44-79.

Markillie, L. M., Varnum, S. M., Hradechy, P. \& Wong, K. K. (1999). Targeted mutagenesis by duplication insertion in the radioresistant bacterium Deinococcus radiodurans: radiation sensitivities of catalase (katA) and superoxide dismutase (sodA) mutants. J Bacteriol 181, 666-669.

Meima, R., Rothfuss, H. M., Gewin, L. \& Lidstrom, M. E. (2001). Promoter cloning in the radioresistant bacterium Deinococcus radiodurans. J Bacteriol 183, 3169-3175.

Misra, H. S., Pandey, P. K., Modak, M. J., Vinayak, R. \& Pandey, V. N. (1998). Polyamide nucleic acid-DNA chimera lacking the phosphate backbone are novel primers for polymerase reaction catalyzed by DNA polymerases. Biochemistry 37, 1917-1925.

Misra, H. S., Khairnar, N. P., Kota, S., Srivastava, S., Joshi, V. P. \& Apte, S. K. (2006). An exonuclease I sensitive DNA repair pathway in Deinococcus radiodurans: a major determinant of radiation resistance. Mol Microbiol 59, 1308-1316.

Moore, M. H., Gulbis, J. M., Dodson, E. J., Demple, B. \& Moody, P. C. (1994). Crystal structure of a suicidal DNA repair protein: the Ada O6-methylguanine-DNA methyltransferase from E. coli. EMBO J 13, 1495-1501.

Narumi, I., Cherdchu, K., Kitayama, S. \& Watanabe, H. (1997). The Deinococcus radiodurans uvrA gene: identification of mutation sites in two mitomycin-sensitive strains and the first discovery of insertion sequence element from deinobacteria. Gene 198, 115-126.

Narumi, I., Satoh, K., Kikuchi, M., Funayama, T., Yanagisawa, T., Kobayashi, Y., Watanabe, H. \& Yamamoto, K. (2001). The LexA protein from Deinococcus radiodurans is not involved in RecA induction following gamma irradiation. J Bacteriol 183, 6951-6956.

O'Brien, P. J. \& Ellenberger, T. (2004). The Escherichia coli 3methyladenine DNA glycosylase AlkA has a remarkably versatile active site. J Biol Chem 279, 26876-26884.

Parikh, S. S., Mol, C. D., Hosfield, D. J. \& Tainer, J. A. (1999). Envisioning the molecular choreography of DNA base excision repair. Curr Opin Struct Biol 9, 37-47.

Prasad, R., Bebenek, K., Hou, E., Shock, D. D., Beard, W. A., Woodgate, R., Kunkel, T. A. \& Wilson, S. H. (2003). Localization of the deoxyribose phosphate lyase active site in human DNA polymerase iota by controlled proteolysis. J Biol Chem 278, 29649-29654.

Sambrook, J. \& Russell, D. W. (2001). Molecular Cloning: a Laboratory Manual, 3rd edn. Cold Spring Harbor, NY: Cold Spring Harbor Laboratory.
Satoh, K., Ohba, H., Sghaier, H. \& Narumi, I. (2006). Downregulation of radioresistance by LexA2 in Deinococcus radiodurans. Microbiology 152, 3217-3226.

Schafer, M., Schmitz, C., Facius, R., Horneck, G., Milow, B., Funken, K.-H. \& Ortner, J. (2000). Systematic study of parameters influencing the action of Rose Bengal with visible light on bacterial cells: comparison between biological effect and singlet-oxygen production. Photochem Photobiol 71, 514-523.

Seeberg, E., Eide, I. \& Bjoras, M. (1995). The base excision repair pathways. Trends Biochem Sci 20, 391-397.

Servant, L., Cazaux, C., Bieth, A., Iwai, S., Hanaoka, F. \& Hoffmann, J. S. (2002). A role for DNA polymerase $\beta$ in mutagenic UV lesion bypass. J Biol Chem 277, 50046-50053.

Sheng, D., Zheng, Z., Tian, B., Shen, B. \& Hua, Y. (2004). LexA analog (dra0074) is a regulatory protein that is irrelevant to $r e c A$ induction. $J$ Biochem 136, 787-793.

Shinohara, A. \& Ogawa, T. (1995). Homologous recombination and the roles of double-strand breaks. Trends Biochem Sci 20, 387-391.

Tudek, B., Van Zeeland, A. A., Kusmierek, J. T. \& Laval, J. (1998). Activity of Escherichia coli DNA-glycosylase on DNA damaged by methylating and ethylating agents and influence of 3-substituted adenine derivatives. Mutat Res 407, 169-176.

White, O., Eisen, J. A., Heildelberg, J. F., Hickey, E. K., Peterson, J. D., Dodson, R. J., Haft, D. H., Gwinn, M. L., Nelson, W. C. \& other authors (1999). Genome sequence of the radioresistant bacterium Deinococcus radiodurans $\mathrm{R} 1$. Science 286, 1571-1577.

Wiebauer, K. \& Jiricny, J. (1990). Mismatch-specific thymine DNA glycosylase and DNA polymerase $\beta$ mediate the correction of G.T mispairs in nuclear extracts from human cells. Proc Natl Acad Sci U S A 87, 5842-5845.

Yamada, M., Nunoshiba, T., Shimizu, M., Gruz, P., Kamiya, H., Harashima, H. \& Nohmi, T. (2006). Involvement of Y-family DNA polymerase in mutagenesis caused by oxidized nucleotides in Escherichia coli. J Bacteriol 188, 4992-4995.

Yoshida, S. \& Cavalieri, L. F. (1971). Multiple molecular species of Escherichia coli DNA polymerase. Proc Natl Acad Sci U S A 68, 200204.

Zahradka, K., Slade, D., Bailone, A., Sommer, S., Averbeck, D., Petranovic, M., Lindner, A. B. \& Radman, M. (2006). Reassembly of shattered chromosomes in Deinococcus radiodurans. Nature 443, 569573.

Edited by: J. Green 